\section{(A) Check for updates}

Cite this: Dalton Trans., 2017, 46, 12015

Received 16th August 2017,

Accepted 21st August 2017

DOI: $10.1039 / \mathrm{c} 7 \mathrm{dt} 03046 \mathrm{k}$

rsc.li/dalton

\title{
Ring expansion of a ring expanded carbene $\uparrow$
}

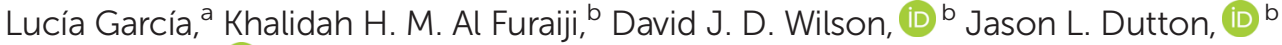 \\ Michael S. Hill (D) *a and Mary F. Mahon ${ }^{a}$
}

Reaction of phenylsilane with the ring expanded carbene 6-Mes results in facile $\mathrm{Si}-\mathrm{H}$ oxidative addition to the carbenic carbon at room temperature. Heating the resultant diorganosilane product induces ring expansion through silicon to carbon migration of either the $\mathrm{Si}-\mathrm{H}$ or $\mathrm{Si}-\mathrm{Ph}$ bonds.

The last quarter century has witnessed the emergence of imidazolylidene and related five-membered $\mathrm{N}$-heterocyclic carbenes (NHCs, e.g. IPr, 1) as one of the most widely applied classes of ligand in contemporary coordination chemistry and catalysis. ${ }^{1}$ While the chemical behaviour of NHCs is now well understood, their ring expanded analogues (RENHCs), derived primarily from six- to eight-membered heterocyclic structures (e.g. 1,3bis(2,4,6-trimethylphenyl)-3,4,5,6-tetrahydropyrim-idin-2-ylidene, 6-Mes, 2), remain relatively underexplored. ${ }^{2}$ In general, the incorporation of additional ring atoms delivers enhanced basicity as a result of larger $\mathrm{N}_{-} \mathrm{C}_{\mathrm{NHC}}-\mathrm{N}$ bond angles and consequent higher HOMO energies. Although this feature provides a further means to modulate the influence of RENHCs when bound to typical metal centres, it may also be anticipated to induce a greater tendency to deleterious side reactions. ${ }^{3}$

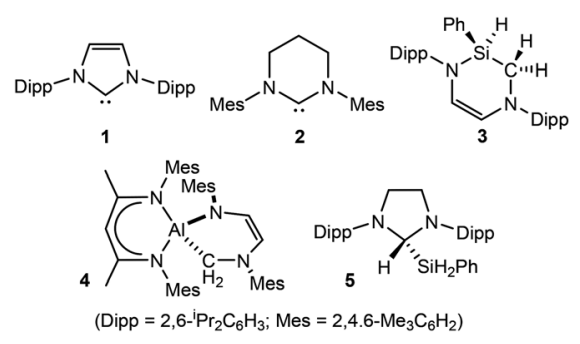

\footnotetext{
${ }^{a}$ Department of Chemistry, University of Bath, Claverton Down, Bath, BA2 7AY, UK. E-mail:m.s.hill@bath.ac.uk

${ }^{b}$ Department of Chemistry and Physics, La Trobe Institute for Molecular Science, La Trobe University, Melbourne, Victoria 3086, Australia

$\dagger$ Electronic supplementary information (ESI) available: Experimental procedures, computational details and details of the X-ray experiments to determine the structures of compounds 6-8. CCDC 1562734 and 1562735. For ESI and crystallographic data in CIF or other electronic format see DOI: 10.1039/c7dt03046k
}

In the context of NHC reactivity, we, and others, have recently highlighted that these five-membered rings may be expanded to six-membered heterocyclic structures (e.g. 3-4), primarily through reactions with the hydridic E-H bonds of a range of silane,${ }^{4}$ borane,${ }^{5-10}$ beryllium ${ }^{11}$ and aluminium ${ }^{12}$ hydride reagents. A number of density functional theory (DFT) computational studies of this reactivity have highlighted that the ring expansion process ensues in each case through a superficially similar reaction sequence. ${ }^{12 a, 13}$ Initial E-H oxidative addition to the carbenic carbon centre provides species such the isolable derivative $5{ }^{4}$ while ring expansion takes place through subsequent insertion of the electropositive main group atom into an endocyclic $\mathrm{C}-\mathrm{N}$ bond. In every case the initial carbene oxidation was identified as the rate determining step in the reaction, with the relative barrier heights reflected in the facility for the individual processes. In this contribution we describe a combination of synthetic and DFT studies, which demonstrate that the increasingly prominent RENHC class of two electron donor ligand is similarly prone to silane-induced ring expansion. Furthermore, we have isolated the initial product of $\mathrm{Si}-\mathrm{H}$ oxidative addition and confirm its intermediacy during the ring opening process.

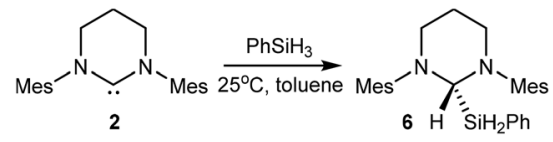

An initial reaction performed in $d_{8}$-toluene between 6-Mes (2) and $\mathrm{PhSiH}_{3}$ was observed to take place with the stoichiometric formation of a single new compound (6) within 30 minutes at room temperature. The production of compound 6 was characterised through the loss of the plane of symmetry comprising the heterocyclic ring of compound 2 . Most notably, the methyl groups of the $N$-mesityl substituents were observed as three unique singlet resonances in the resultant ${ }^{1} \mathrm{H}$ NMR spectrum at $\delta 2.57,2.18$ and $2.12 \mathrm{ppm}$, each of which as $6 \mathrm{H}$ signals by relative integration. In addition, a further triplet resonance, which integrated as a single proton, 


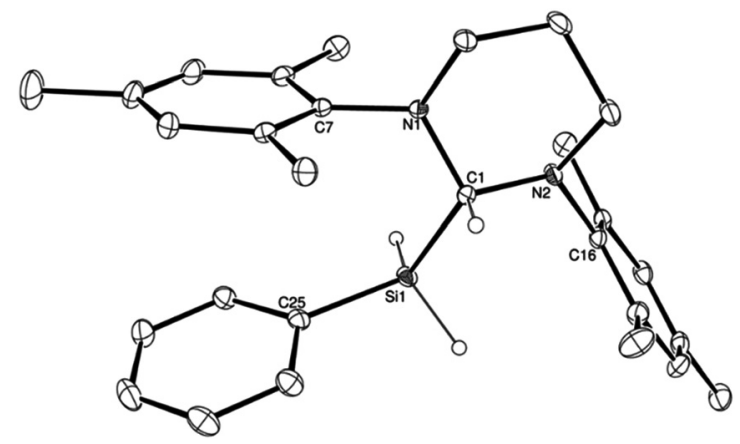

Fig. 1 ORTEP representation of compound 6 with 25\% probability ellipsoids. Hydrogen atoms, except those attached to $\mathrm{C} 1$ and Sil are removed for clarity. Selected bond lengths $(\AA)$ and angles $\left({ }^{\circ}\right)$ : Si1-C1 1.9122(17), Si1-C25 1.8666(18), N1-C1 1.465(2), N1-C7 1.439(2), N2-C1 1.469(2), N2-C16 1.435(2), C25-Si1-C1 115.64(7), N1-C1-Si1 113.23(11), N1-C1-N2 106.71(13), N2-C1-Si1 110.45(11).

at $\delta 5.30 \mathrm{ppm}$ and a correlated $(2 \mathrm{H})$ doublet signal at $\delta$ $4.01 \mathrm{ppm}$ were strongly reminiscent of the respective $\mathrm{C}-\mathrm{H}$ and $\mathrm{Si} \mathrm{H}_{2} \mathrm{Ph}$ signals reported by Bertrand and co-workers for compound $5,{ }^{14}$ which resulted from analogous room temperature oxidative addition of $\mathrm{PhSiH}_{3}$ to the saturated imidazolidin-2-ylidene analogue of compound 1. Similar solution NMR observations have also been described as a result of the migratory insertion reactions of diamidocarbene (DAC) ligands with a variety of $\mathrm{B}-\mathrm{H},{ }^{15} \mathrm{~B}-\mathrm{B}$ and $\mathrm{Cu}-\mathrm{H}$ functionalities, ${ }^{16}$ while cyclic (alkyl)(amino)carbenes have recently been reported to react at room temperature with the $\mathrm{Si}-\mathrm{H}$ bonds of both organosilanes and hydrogen-terminated silicon surfaces. ${ }^{17}$ On this basis we were able to ascribe compound 6 as a similar product of $\mathrm{Si}-\mathrm{H}$ oxidative addition, (6-Mes- $\mathrm{H}$ ) $\mathrm{SiH}_{2} \mathrm{Ph}$ (eqn (1)), a deduction that was confirmed by a subsequent X-ray diffraction analysis performed on a single crystal obtained by slow evaporation of a pentane solution. The results of this analysis are shown in Fig. 1, while selected bond length and angle data are provided in the figure caption.

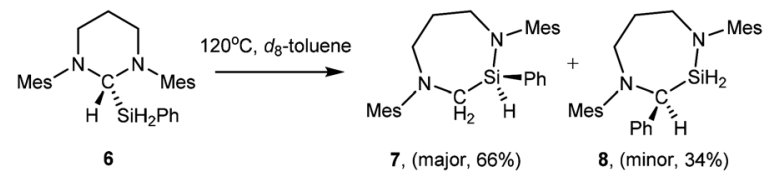

Radius has previously reported that compound 5 undergoes ring expansion to provide the fully saturated analogue of compound 3 when heated to $100{ }^{\circ} \mathrm{C}$ for 5 hours. ${ }^{4}$ Accordingly, a $d_{8^{-}}$ toluene solution of compound 6 was observed by ${ }^{1} \mathrm{H}$ NMR spectroscopy to undergo complete conversion to a mixture of two new isomeric compounds, 7 and 8, which were observed to form in a respective $2: 1$ ratio after heating at $120^{\circ} \mathrm{C}$ for four days. The major species (7) displayed a single $\mathrm{Si}-\mathrm{H}$ environment $\left({ }^{1} J_{\mathrm{SiH}}=204.4 \mathrm{~Hz}\right)$ as a doublet resonance at $\delta 5.39 \mathrm{ppm}$, whereas the $\mathrm{Si}-\mathrm{H}$ environments of the minor component (8) appeared as two mutually coupled doublet of doub- (a)

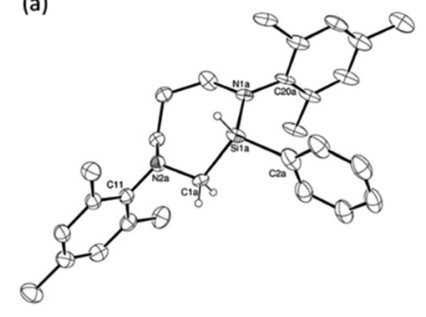

(b)

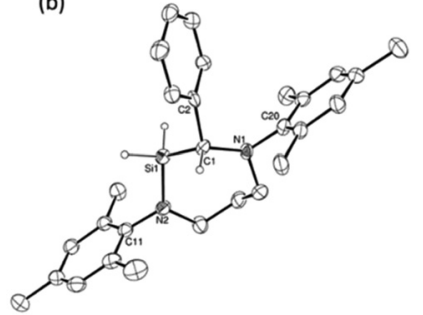

Fig. 2 (a) ORTEP representation of compound 7 with $25 \%$ probability ellipsoids. Hydrogen atoms, except those attached to C1a and Sila are removed for clarity. (b) ORTEP representation of compound 8 with $25 \%$ probability ellipsoids. Hydrogen atoms, except those attached to $\mathrm{C} 1$ and Si1 are removed for clarity.

lets and doublet signals $\left({ }^{2} J_{\mathrm{HH}}=10.8 \mathrm{~Hz}\right)$ centred at $\delta 5.06$ and 4.13 ppm, respectively.

The origin of these observations was resolved by the isolation of compounds 7 and 8, which crystallised as single cocrystals from pentane solution. The resultant X-ray diffraction analysis revealed the two compounds to be isomers resulting from formal transfer of either two silane hydrogen atoms (7, eqn (2) and Fig. 2a) or one silane hydrogen and one phenyl substituent (8, eqn (2) and Fig. 2b) to the $\mathrm{N}_{2} \mathrm{C}$ heterocyclic carbon centre of 2 . Resolution of the electron density in the co-crystal required modelling of the disorder over two proximate positions that pertained to atoms Si1, N1, N2, C1-C7 and the carbon atoms of the C20-containing $N$-mesityl group. Although the constitution of the two isomers was confirmed by the location and refinement of the hydrogen atoms attached to the silicon centres, the disorder ratio, 34(7):66 (8), in the solid state was not representative of the isomer ratio evident in the ${ }^{1} \mathrm{H}$ NMR spectrum of the reaction mixture.

The greater facility for hydrogen-to-carbon over phenyl-tocarbon transfer implied by the in situ NMR analysis is consistent with Radius and co-workers' earlier observation that higher reaction temperatures are necessary to effect NHC ring opening with $\mathrm{Ph}_{3} \mathrm{SiH}$ in comparison to $\mathrm{Ph}_{2} \mathrm{SiH}_{2}$ and $\mathrm{PhSiH}_{3}$. To further inform our understanding of the RENHC ring expansion process, SCS-MP2/def2-TZVP(acetonitrile-PCM)// M06-2X/def2-TZVP calculations on a model system with $\mathrm{N}$-Ph NHC substituents were performed to examine the thermochemical properties of the two competing pathways. The results were similar to those previously elucidated by our group and others on the mechanism for the analogous expansion reaction with the five-membered carbene rings, ${ }^{12,13}$ and are consistent with the current experimental observations. The two pathways follow a common first step with the transfer of a hydride from silicon to the carbene carbon and formation of a Si-C bond via T1 forming B (Fig. 3). The second step involves ring-opening of the endocyclic carbene $\mathrm{C}-\mathrm{N}$ bond giving $\mathbf{C}$ via $\mathbf{T} 2$. The relative barrier for these two steps show strong basis set and method dependence (see ESI $\uparrow$ for method and basis set results). At the SCS-MP2/def2-TZVP 


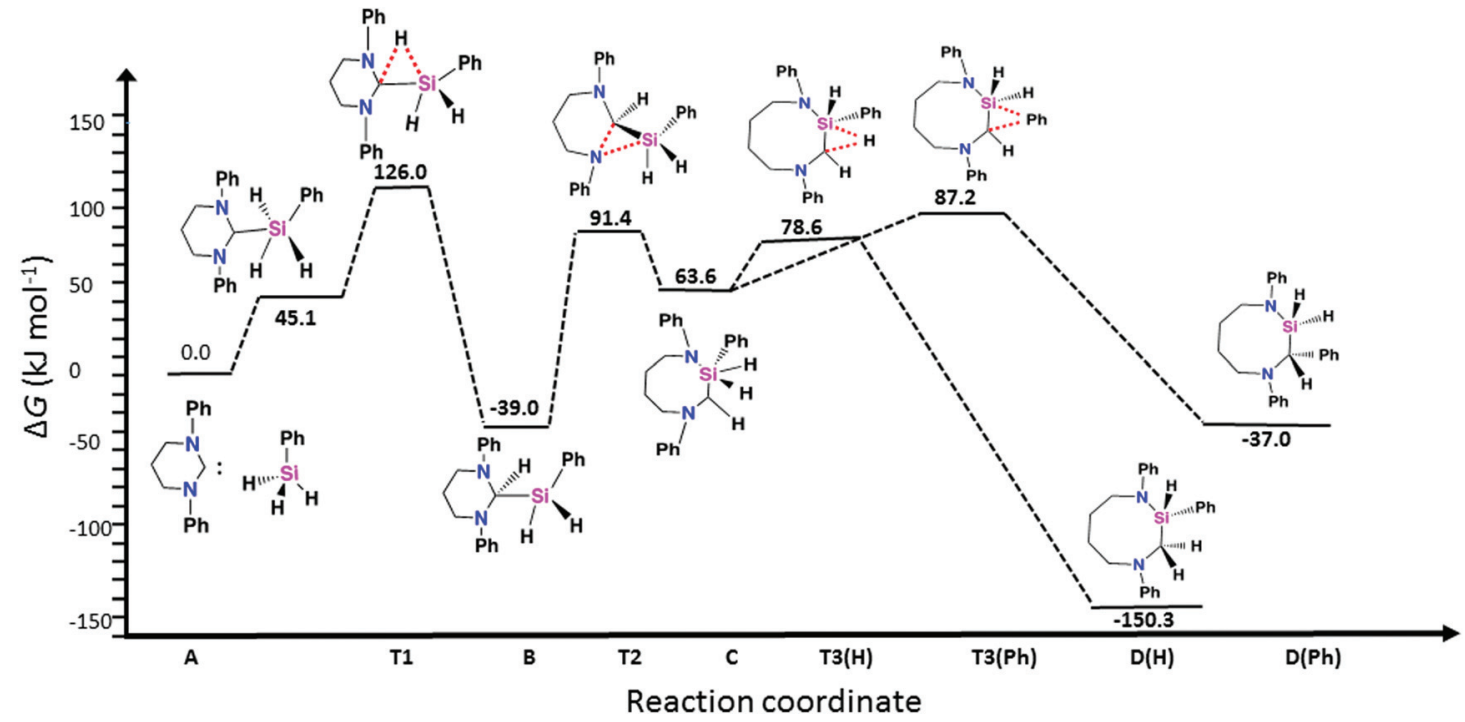

Fig. 3 Calculated reaction profile (SCS-MP2/def2-TZVP, including implicit MeCN solvent model).

level the barriers are very similar at 126 (T1) and 130 (T2) $\mathrm{kJ} \mathrm{mol}{ }^{-1}$. Most methods considered tend to favour T2 as rate determining, consistent with the experimental observations.

The third step onwards from $\mathbf{C}$ discriminates the two observed products, for which the major product arising from a second hydride migration is both thermodynamically and kinetically favoured over the minor phenyl migration product. The barrier for the second hydride migration (T3H) is 15 $\mathrm{kJ} \mathrm{mol}^{-1}$, while for phenyl migration (T3Ph) it is $24 \mathrm{~kJ} \mathrm{~mol}^{-1}$. The overall hydride migration product is $111 \mathrm{~kJ} \mathrm{~mol}^{-1}$ lower in free energy than $\mathbf{B}$, while the phenyl migration product is nearly equal in energy to B. Overall, from the starting carbene and phenylsilane, the $\Delta G$ for the two reactions are $-150 \mathrm{~kJ} \mathrm{~mol}^{-1}$ and $-37 \mathrm{~kJ} \mathrm{~mol}^{-1}$ for secondary hydride and phenyl migration, respectively.

In conclusion, we have described the first example of a main group-centred ring expansion reaction of a ring expanded carbene. These results demonstrate that the previously observed potential for $\mathrm{E}-\mathrm{H}$ oxidative addition and ring expansion of NHCs must be a similar consideration in the development of future applications of RENHCs. We are continuing to study this and related reactivity.

\section{Conflicts of interest}

There are no conflicts of interest to declare.

\section{Acknowledgements}

We thank the EPSRC (MSH: EP/N014456/1) and ARC (DJDW: DP160103046, JLD: FT160100007) for funding, and La Trobe University, Intersect, and NCI for grants of computing.

\section{Notes and references}

1 (a) W. A. Herrmann, Angew. Chem., Int. Ed., 2002, 41, 1290; (b) S. Diez-Gonzalez, N. Marion and S. P. Nolan, Chem. Rev., 2009, 109, 3612.

2 J. Li, W.-X. Shen and X.-R. Li, Curr. Org. Chem., 2012, 16, 2879.

3 For reviews of NHC degradation, see: (a) C. M. Crudden and D. P. Allen, Coord. Chem. Rev., 2004, 248, 2247; (b) K. J. Cavell, Dalton Trans., 2008, 6676; (c) M. Albrecht, Chem. Rev., 2010, 110, 576; (d) S. Würtemberger-Pietsch, U. Radius and T. B. Marder, Dalton Trans., 2016, 45, 5880.

4 D. Schmidt, J. H. J. Berthel, S. Pietsch and U. Radius, Angew. Chem., Int. Ed., 2012, 51, 8881.

5 S. M. I. Al-Rafia, R. McDonald, M. J. Ferguson and E. Rivard, Chem. - Eur. J., 2012, 18, 13810.

6 S. Kumar Bose, K. Fucke, L. Liu, P. G. Steel and T. B. Marder, Angew. Chem., Int. Ed., 2014, 53, 1799.

7 T. Wang and D. W. Stephan, Chem. - Eur. J., 2014, 20, 3036. 8 D. Franz and S. Inoue, Chem. - Asian J., 2014, 2083.

9 S. Pietsch, U. Paul, I. A. Cade, M. J. Ingleson, U. Radius and T. B. Marder, Chem. - Eur. J., 2015, 21, 9018.

10 S. Würtemberger-Pietsch, H. Schneider, T. B. Marder and U. Radius, Chem. - Eur. J., 2016, 22, 13032.

11 (a) M. Arrowsmith, M. S. Hill, G. Kociok-Köhn, D. J. MacDougall and M. F. Mahon, Angew. Chem., Int. Ed., 2012, 51, 2098; (b) M. Arrowsmith, M. S. Hill and G. Kociok-Köhn, Organometallics, 2015, 34, 653.

12 (a) M. D. Anker, A. L. Colebatch, K. J. Iverson, D. J. D. Wilson, J. L. Dutton, L. García, M. S. Hill, D. J. Liptrot and M. F. Mahon, Organometallics, 2017, 36, 1173; (b) H. Schneider, A. Hock, R. Bertermann and U. Radius, Chem. - Eur. J., 2017, DOI: 101002/ chem.201702166.

13 (a) K. J. Iversen, D. J. D. Wilson and J. L. Dutton, Dalton Trans., 2013, 42, 11035; (b) K. J. Iversen, D. J. D. Wilson and 
J. L. Dutton, Organometallics, 2013, 32, 6209; (c) K. J. Iversen, D. J. D. Wilson and J. L. Dutton, Dalton Trans., 2015, 44, 3318; (d) P. Hemberger, A. Bodi, J. H. J. Berthel and U. Radius, Chem. - Eur. J., 2015, 21, 1434; (e) M. R. Momeni, E. Rivard and A. Brown, Organometallics, 2013, 32, 6658; $(f)$ M.-D. Su, Inorg. Chem., 2014, 53, 5080. For a review of progress in this area, see: (g) K. J. Iversen, D. H. D. Wilson and J. L. Dutton, Dalton Trans., 2014, 43, 12807.
14 G. D. Frey, J. D. Masuda, B. Donnadieu and G. Bertrand, Angew. Chem., Int. Ed., 2010, 49, 9444.

15 D. N. Lastovickova and C. W. Bielawski, Organometallics, 2016, 35, 706.

16 L. R. Collins, I. M. Riddlestone, M. F. Mahon and M. K. Whittlesey, Chem. - Eur. J., 2015, 21, 14075.

17 A. V. Zhukhovitskiy, M. G. Mavros, K. T. Queeney, T. Wu, T. Van Voorhis and J. A. Johnson, J. Am. Chem. Soc., 2016, 138, 8639. 